\title{
The Role of Brain Connectome Imaging in the Estimation of Depressive Relapse Risk
}

\section{Bildgebung des Gehirn-Konnektoms und depressives Rezidivrisiko}

Authors

Felix Brandl, Chun Meng, Claus Zimmer, Christian Sorg

\section{Affiliation}

Department of Neuroradiology and Department of Psychiatry, Klinikum rechts der Isar, Technical University Munich, Germany

Key words

brain, MR-functional imaging, functional connectivity, graph theory, major depressive disorder

received 14.01.2018

accepted 26.04.2018

Bibliography

DOI https://doi.org/10.1055/a-0628-7260

Published online: 13.8.2018

Fortschr Röntgenstr 2018; 190: 1036-1043

(c) Georg Thieme Verlag KG, Stuttgart · New York

ISSN 1438-9029

Correspondence

Dr. Felix Brand

Abteilung für Diagnostische und Interventionelle

Neuroradiologie, Klinikum rechts der Isar,

Technische Universität München, Ismaninger Str. 22,

81675 Munich, Germany

Tel.: ++ 49/89/41404683

felix.brandl@tum.de

\section{ZUSAMMENFASSUNG}

Hintergrund Ungefähr zwei Drittel aller Patienten mit depressiver Störung (major depressive disorder, MDD) erleiden ein Rezidiv. Die Mechanismen des depressiven Rezidivs sind allerdings noch wenig verstanden. In den letzten Jahren wurde zunehmend das Konnektom des Gehirns untersucht, um mögliche Biomarker eines depressiven Rezidivs zu identifizieren. Der Begriff „Konnektom“ beschreibt die Karte aller struktureller und funktioneller Verbindungen des Gehirns. Es kann mittels struktureller oder funktioneller Magnetresonanztomografie und anschließender Graphentheorie-basierter Analyse untersucht werden, um die Netzwerk-Topologie auf globaler und regionaler Ebene zu beschreiben.

Methode Diese Übersichtsarbeit basiert auf einer selektiven Literaturrecherche in PubMed, die den aktuellen Forschungsstand repräsentiert, sowie auf einer eigenen bereits publizierten Arbeit, die mit dem Promotionspreis der Deutschen Röntgengesellschaft ausgezeichnet wurde.
Ergebnisse und Schlussfolgerungen Zahlreiche Studien zeigen, dass eine veränderte Netzwerk-Topologie, z. B. von Default-mode Netzwerk und Striatum, eine entscheidende Rolle in der Pathophysiologie der Depression spielt. Unsere Arbeitsgruppe konnte zeigen, dass striatale Netzwerk-Zentralität (oder Hubness) mit der Anzahl depressiver Episoden assoziiert ist, welche einer der besten Prädiktoren für ein depressives Rezidiv ist. Diese Daten legen aberrante striatale Netzwerk-Topologie als möglichen Biomarker eines depressiven Rezidivs nahe. Die Translation dieser vielversprechenden Befunde in die klinische Routine-Diagnostik wird durch zahlreiche methodologische Vorteile befördert, wohingegen einige ungelöste Probleme diesen Prozess noch behindern.

\section{Kernaussagen}

- Ungefähr zwei Drittel aller Patienten mit Depression erleiden ein Rezidiv.

- Die Mechanismen des depressiven Rezidivs sind noch wenig verstanden.

- Die Bildgebung des Gehirn-Konnektoms kann zum besseren Verständnis des depressiven Rezidivs beitragen.

- Der Begriff „Konnektom“ umfasst alle strukturellen und funktionellen Verbindungen/Netzwerke des Gehirns.

- Eine veränderte striatale Netzwerk-Topologie könnte mit dem depressiven Rezidivrisiko assoziiert sein.

\section{ABSTRACT}

Background About two-thirds of all patients with major depressive disorder (MDD) suffer from depressive relapse, the mechanisms of which are still poorly understood. In recent years, analyses of the brain's connectome have increasingly been employed to identify potential biomarkers of depressive relapse. The term "connectome" refers to the map of all structural or functional connections in the brain. It can be investigated by structural or functional magnetic resonance imaging followed by graph theory-based analysis to characterize network topology on the global and regional level.

Methods This review is based on a selective literature search in PubMed representing the current state of research, as well as on an already published study which was awarded the Promotionspreis of the Deutsche Röntgengesellschaft.

Results and Conclusion Numerous studies point to altered network topology, e. g., of default-mode network and striatum, as being crucial for the pathophysiology of MDD. Our 
group was able to show that striatal centrality (or hubness) is associated with the number of depressive episodes, which is one of the best predictors for depressive relapse. These data suggest aberrant striatal network topology as a potential biomarker for depressive relapse risk. The translation of these promising findings into clinical routine diagnostics is promoted by several methodological advantages, while some unresolved issues still hinder this process.

\section{Key points}

- About two-thirds of all patients with MDD suffer from depressive relapse.

- The mechanisms of depressive relapse are still poorly understood.
- Imaging the brain's connectome can contribute to better understanding of depressive relapse.

- The term "connectome" comprises all structural and functional connections of the brain.

- Altered striatal network topology could be associated with depressive relapse risk.

\section{Citation Format}

- Brandl F, Meng C, Zimmer C et al. The Role of Brain Connectome Imaging in the Estimation of Depressive Relapse Risk. Fortschr Röntgenstr 2018; 190: 1036-1043

\section{Introduction}

With a lifetime prevalence of about 19\% [1], major depressive disorder (MDD) is one of the most frequent psychiatric disorders worldwide. Symptoms comprise depressed mood, loss of pleasure and motivation, and vegetative impairments [2]. Furthermore, suicide risk is increased to about $6 \%$ [3]. $35-87 \%$ of patients suffer from recurrent MDD, which refers to the occurrence of at least 2 major depressive episodes [4, 5]. The number of previous depressive episodes and residual sub-depressive symptoms represent the most important clinical markers to predict the risk of depressive relapse [4]. However, concerning biomarkers of depressive relapse risk, currently the only candidate is reduced volume of the hippocampus, which can be measured by structural magnetic resonance imaging (MRI). Several meta-analyses showed consistently reduced hippocampal gray matter volume in MDD $[6,7]$. Hippocampus volume correlates negatively with the number of depressive episodes, i. e., the more depressive episodes, the more pronounced the volume reduction $[6,8]$. Interestingly, hippocampal volume reduction is associated with a worse clinical outcome, particularly with depressive relapse $[9,10]$.

Other reliable candidates for biomarkers are missing so far. However, whole-brain connectome analyses might represent promising tools for the detection of future biomarkers of depressive relapse risk.

\section{MDD as disorder of the connectome}

\section{The concept of connectome}

Depression has been associated with widespread structural and functional brain changes on multiple levels, from microscopic to macroscopic. To describe such widespread brain impairments, the concept of "connectome" was introduced, which describes the complete map of structural and/or functional connections in the brain [11]. On the macroscopic level, these structural and functional connections can be investigated by MRI [12]. Concerning structural connections, the term "structural connectivity" refers to anatomical fiber pathways in the white matter linking spatially distinct brain regions; it is usually measured via diffusion tensor imaging, followed by computational tractography to quantify and visualize fiber tracts [12]. Concerning functional connections, the term "intrinsic functional connectivity" describes the synchronicity of spontaneous infra-slow $(<0.1 \mathrm{~Hz})$ fluctuations in blood oxygenation, which can be measured by resting-state functional MRI (rs-fMRI) via the "blood oxygenation level-dependent" (BOLD) signal $[13,14]$. Technically, the BOLD signal depends on T2* relaxation, which is influenced by the ratio of oxygenated versus deoxygenated hemoglobin [15]. Via a process called neurovascular coupling, neuronal activity leads to a local increase of cerebral blood flow and an influx of oxyhemoglobin that exceeds oxygen consumption [16]. Therefore, the BOLD signal represents an indirect marker of neuronal activity with a delay of about 1 to 3 seconds [17]. Spontaneous fluctuations of the BOLD signal are measured by acquiring multiple rs-fMRI volumes (e.g., over $10 \mathrm{~min}$ ) with the subject lying in the scanner without any specific stimulation (as opposed to task paradigms). If the BOLD time series of two brain regions are correlated, this coherence is termed "intrinsic functional connectivity".

The brain's connectome can be investigated by parcellating the brain into distinct regions (for example, based on histologyderived brain atlases) and measuring the structural or functional connectivity between each pair of regions $[12,18]$. This yields a so-called "connectivity matrix", which can also be thought of as network or graph ( $\triangleright$ Fig. 1). A graph consists of "nodes" (= brain regions) and "edges" connecting these nodes (= connectivity between regions). Fundamental topological properties of such a graph can then be described mathematically by graph theorybased approaches. Graph theory quantifies properties like segregation, integration, or centrality by several graph scores both on the global and nodal level. Segregation describes the brain's ability of specialized information processing in densely connected clusters or modules; it can be quantified by the so-called "clustering coefficient" (= interconnectedness of neighboring nodes). Integration, in contrast, refers to the ability of rapid information transfer across remote brain regions; it can be quantified by the so-called "characteristic path length" (= shortest sequence of edges needed to travel from one node to another) or "global 
Brain parcellation by atlas

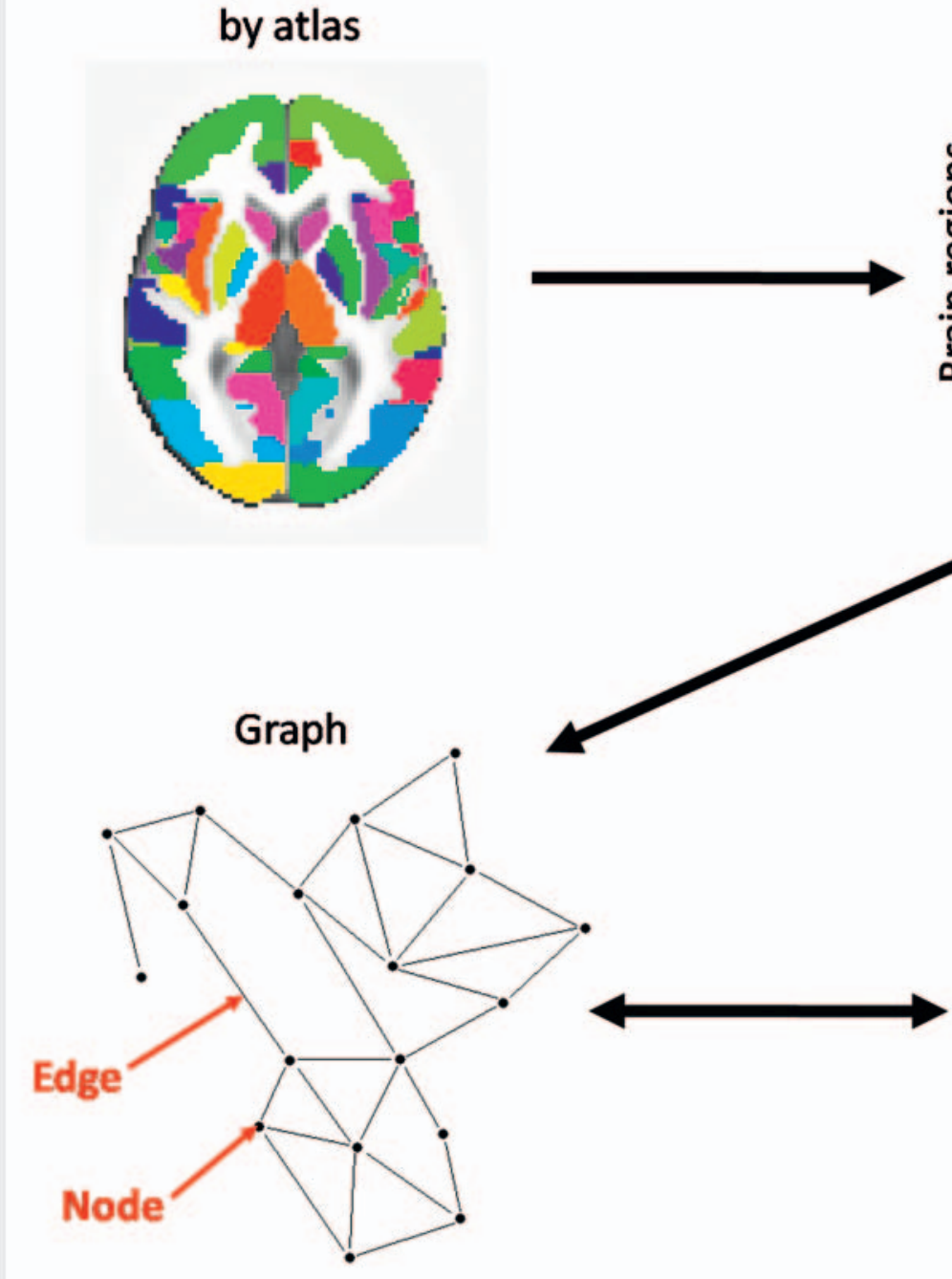

\section{Functional MRI time courses}

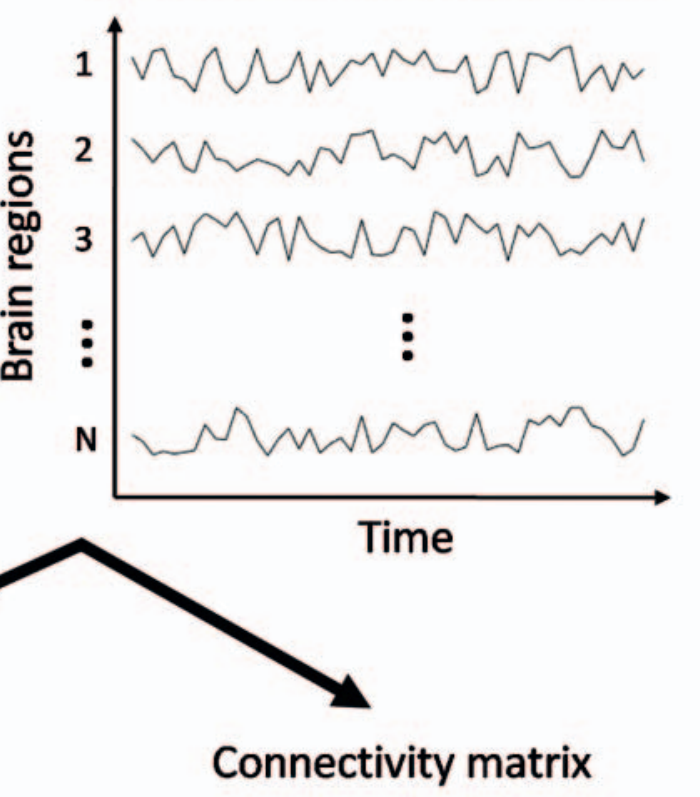

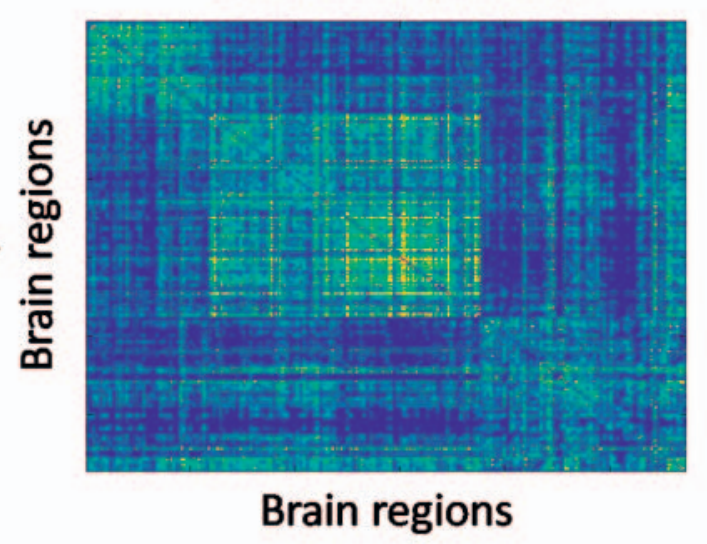

- Fig. 1 Workflow of functional connectome analyses. After parcellation of the brain using predefined regions of interest from brain atlases, functional MRI time courses are extracted from each region. By computing the temporal coherence between each pair of regions (= functional connectivity), a connectivity matrix is constructed. Each element of the connectivity matrix reflects the functional connectivity between two regions (hot colors indicate high connectivity). The connectivity matrix can also be displayed as a graph, consisting of nodes and edges. Nodes are brain regions; edges represent functional connectivity between regions. MRI = magnetic resonance imaging.

- Abb. 1 Arbeitsschritte einer funktionellen Konnektom-Analyse. Nach Parzellierung des Gehirns mittels vordefinierter Regions of interest aus Gehirnatlanten werden die funktionellen MRT-Zeitserien jeder Region extrahiert. Mittels Berechnung der zeitlichen Kohärenz zwischen jedem Paar von Regionen (= funktionelle Konnektivität) wird eine Konnektivitäts-Matrix erstellt. Jedes Element dieser Konnektivitäts-Matrix reflektiert die funktionelle Konnektivität zwischen zwei Regionen (warme Farben zeigen hohe Konnektivität an). Die Konnektivitäts-Matrix kann auch als Graph, der aus Knoten und Kanten besteht, dargestellt werden. Knoten sind Gehirnregionen; Kanten repräsentieren funktionelle Konnektivität zwischen Regionen. MRI = magnetic resonance imaging.

efficiency", its inverse. On the nodal level, this corresponds to the measures "average shortest path length" and "nodal efficiency" ( $\triangleright$ Fig. 2). Centrality or hubness describes how strongly a node is connected to all other nodes of the graph; it can be quantified by the so-called "degree" (= number of edges connected to a certain node) ( $\triangleright$ Fig. 2). For a detailed definition of these and more graph scores, please see [18].
Graph theory is widely applied in the world of science, for example to social [19], metabolic [20], or air transportation networks [21]. Focusing on the brain, "connectomics" (i. e., the study of the brain connectome) has been employed to compare the organization of neural systems across species [22] and across scales, i. e., from microscopic to macroscopic [23]. Concerning human brain diseases, graph-theoretical approaches have been applied to study the pathophysiology of multiple disorders (for 


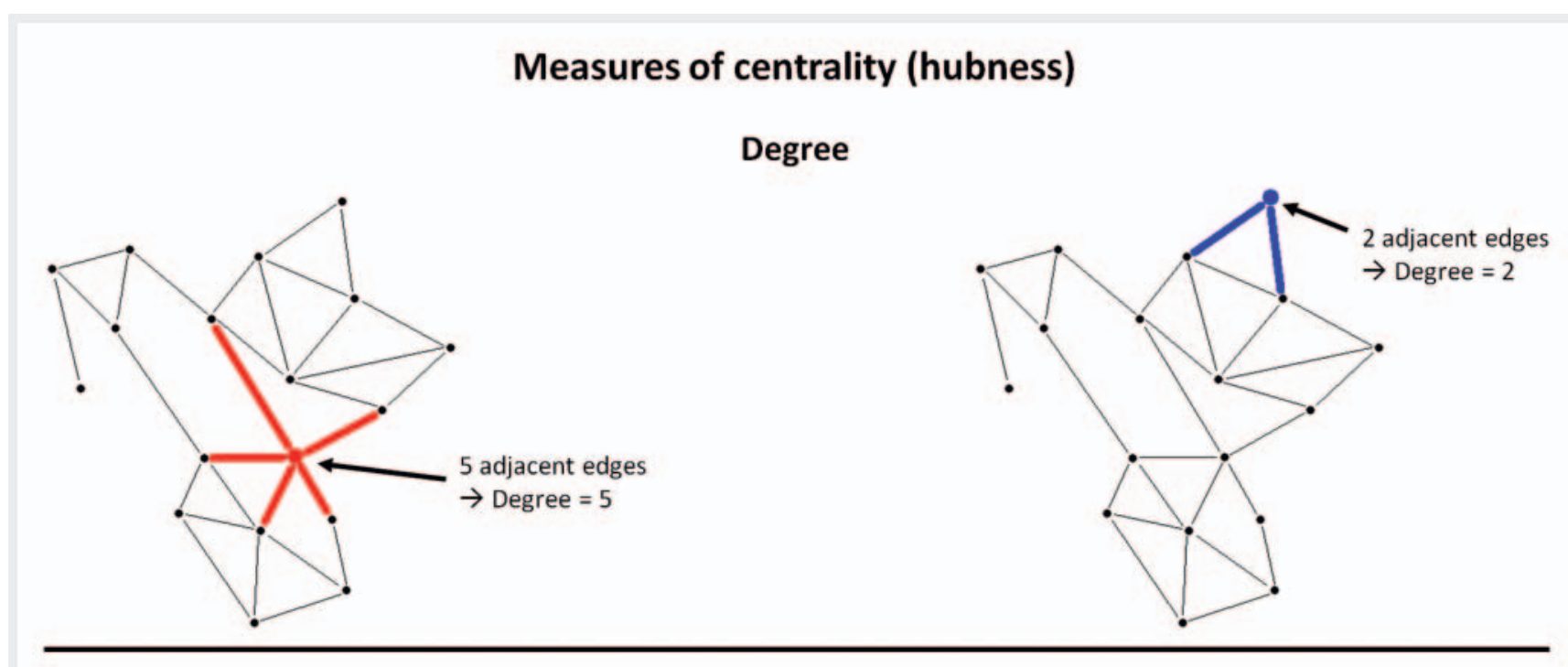

Nodal efficiency

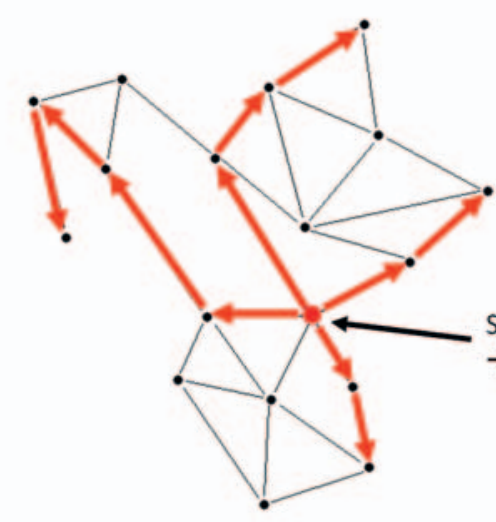

Short paths to other nodes

$\rightarrow$ High nodal efficiency

- Fig. 2 Measures of centrality (hubness). The concept of the nodal graph scores "degree" and "nodal efficiency" is illustrated. Degree is defined as the sum of edges connected to a node. Nodal efficiency is defined as the average inverse shortest path length of a node. A shortest path is the shortest sequence of edges needed to travel from one node to another.

- Abb. 2 Zentralitäts (Hubness)-Scores. Diese Abbildung illustriert die Konzepte der nodalen Graphen-Scores „Degree“ (Knotengrad) und „Nodal efficiency“" (Nodale Effizienz). Degree ist definiert als die Summe aller Kanten, die mit einem Knoten verbunden sind. Nodal efficiency ist definiert als die durchschnittliche inverse kürzeste Pfadlänge eines Knotens. Ein kürzester Pfad ist die kürzeste Abfolge von Kanten, die von einem Knoten zu einem Anderen durchquert werden muss.

recent reviews see [24 - 27]), like Alzheimer's disease [28], Parkinson's disease [29], multiple sclerosis [30], traumatic brain injury [31], epilepsy [32], schizophrenia [33, 34], obsessive-compulsive disorder [35, 36], or MDD. Findings of connectome changes in MDD are presented in detail in the following paragraphs.

\section{Aberrant connectome in MDD}

Alterations of the structural connectome, i. e. impaired white matter tracts, in MDD were investigated by diffusion tensor imaging studies [27]. Consistent results across studies comprise impaired global integration and, on the nodal level, aberrant white matter integrity in default-mode and prefrontal-limbic networks [37 - 39]. Changes in prefrontal-limbic circuits correlate with disease severity and duration [39]. Interestingly, these circuits are affected by electroconvulsive therapy and their structural connectivity alterations correlate with reduction of depressive symptoms [40].

The functional connectome in MDD, on the other hand, was analyzed by rs-fMRI studies (for comprehensive review see [27]). Concerning global topological alterations of the functional connectome, findings remain inconsistent, including reports of increased [41], decreased [42], and unchanged [43, 44] global integration. These inconsistencies could be caused by the different subject samples in the studies: Zhang and colleagues investigated first-episode patients [41], Meng \& Brandl and colleagues studied patients with recurrent MDD [42], and Lord and colleagues recruited a mixed sample [43]. Bohr and colleagues, on the 
other hand, investigated late-life depression, which might involve age-related brain changes [44].

The most interesting findings of altered functional connectome in MDD concern aberrant nodal (i. e., regional) topology: On the cortical level, several studies report increased nodal centrality of regions of the default-mode network (a large-scale brain network encompassing medial prefrontal, medial temporal, posterior cingulate, and parietal cortices) and salience network (anterior cingulate and insula) [41, 45]. Importantly, these changes are associated with severity of depressive symptoms and illness duration $[41,42,45]$. On the subcortical level, studies highlight the role of striatal network topology for MDD. Investigating patients in their first major depressive episode, Zhang and colleagues found increased centrality (=hubness) in the caudate nucleus and putamen [41]. Crucially, centrality of the left caudate nucleus was positively correlated with disease severity, i. e., the worse the symptoms, the more central its role in the global brain network. Using a module-based approach, another study identified enhanced functional connectivity between the amygdala and putamen and reduced connectivity between the insula and putamen, confirming the striatum's central role in depressive pathophysiology [46].

\section{Aberrant functional connectome in MDD as candidate biomarker for relapse risk}

Stimulated by these promising findings, our group conducted a study to further investigate which changes in functional network topology could serve as candidate biomarkers for depressive relapse risk [42]. Based on the observation that the number of depressive episodes is one of the strongest relapse predictors, we hypothesized that specific alterations of the functional connectome in recurrent MDD are associated with the number of depressive episodes. Using rs-fMRI data from 25 patients with recurrent MDD ( 2 to 10 depressive episodes) and 25 healthy controls (matched by age and gender), we defined 112 cortical and subcortical brain regions based on a canonical atlas and employed graph theory-based analysis. We found significantly increased centrality in the right putamen of patients as opposed to significantly decreased centrality of the bilateral caudate (permutation test, $p<0.009$ to correct for multiple comparisons). Critically, the centrality of the right putamen and right accumbens was significantly positively correlated with the number of depressive episodes (partial correlation, $p<0.009$ to correct for multiple comparisons) ( $\vee$ Fig. 3). This means that the more episodes a patient has experienced, the more central the striatum's role in the functional whole-brain network is. These results were independent of medication, current symptom severity, total disease duration in years, and brain atrophy, which were controlled for in the partial correlation analysis. For more details on methods and results, please see the original article in which these findings were published [42].

Since the number of depressive episodes is one of the best predictors of depressive relapse, these results point to aberrant striatal network topology as a potential biomarker for depressive relapse risk. Future studies should further evaluate this result. One exemplary application might be a longitudinal design in which patients are scanned during a phase of depressive remission. After the end of the observation period, the data could then be analyzed in a post-hoc fashion, comparing patients with depressive relapse to patients without relapse.

\section{Possible transfer of connectome-based biomarkers into the clinical routine}

In the following, we will discuss aspects both in favor of and against a translation of these research findings into the clinical routine.

\section{Advantages}

Several aspects qualify rs-fMRI-based connectome analysis as a candidate for clinical routine diagnostics. First and foremost, magnetic resonance imaging does not use ionizing radiation. More specifically, rs-fMRI-based connectome imaging does not require the use of contrast agents with their potential side effects. As currently no long-term adverse effects of MRI are known, this means that connectome imaging could be repeated several times without harm for the patient. Possible applications might be regular rs-fMRI scans (e. g., every six months) to assess the individual relapse risk of a patient.

Second, rs-fMRI sequences are constantly becoming faster due to improved imaging techniques, thus increasingly qualifying them for use in the clinical routine. A significant improvement has been provided by multiband imaging, which means that two or more slices are acquired simultaneously $[47,48]$. For example, applying a multiband factor of 2 makes it possible to halve the scan time or to increase spatial resolution while keeping the scan time stable. For example, current rs-fMRI protocols in our institute comprise the acquisition of 200 volumes with a TR of $2.7 \mathrm{~s}$ (thus amounting to a total scan time of $9 \mathrm{~min}$ ) and a spatial resolution of $2 \times 2 \times 2 \mathrm{~mm}$ voxel size.

Third, rs-fMRI can be integrated with other modalities such as anatomical MRI to complement functional information with structural information. Structural MRI is already performed frequently in major depression to exclude organic causes of symptoms.

Fourth, rs-fMRI is independent of the patient's cognitive capacities, in contrast to task-fMRI protocols. Therefore, it is also suitable for older patients or patients with limited language skills, since no special instruction has to be understood.

Fifth, connectome analyses can be automated easily via fixed software pipelines, meaning that no advanced IT skills are required of the examiner. This certainly represents an important factor for translating new approaches into the clinical routine.

\section{Limitations and Disadvantages}

Nevertheless, there are still important obstacles hindering the application of rs-fMRI-based connectome analysis in clinical routine diagnostics. First, the neurophysiology of the BOLD signal, which is measured by rs-fMRI as the basis for functional connectome analyses, is still not well understood [16, 49]. A high correspondence between BOLD signal and underlying neuronal activity was shown by several animal studies [50-52], justifying its cur- 


\section{Region of interest}

\section{Association between nodal topology and number of depressive episodes}

\section{Right Putamen}
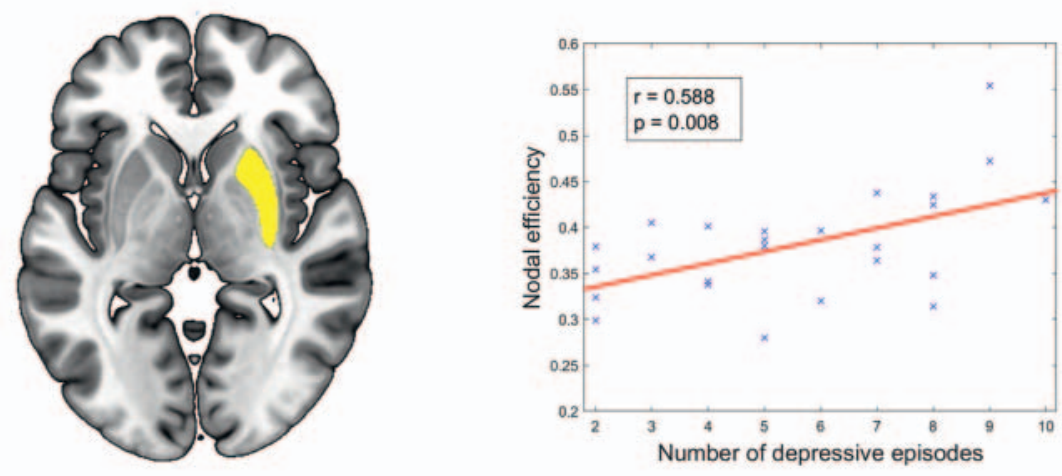

Right Ncl. accumbens
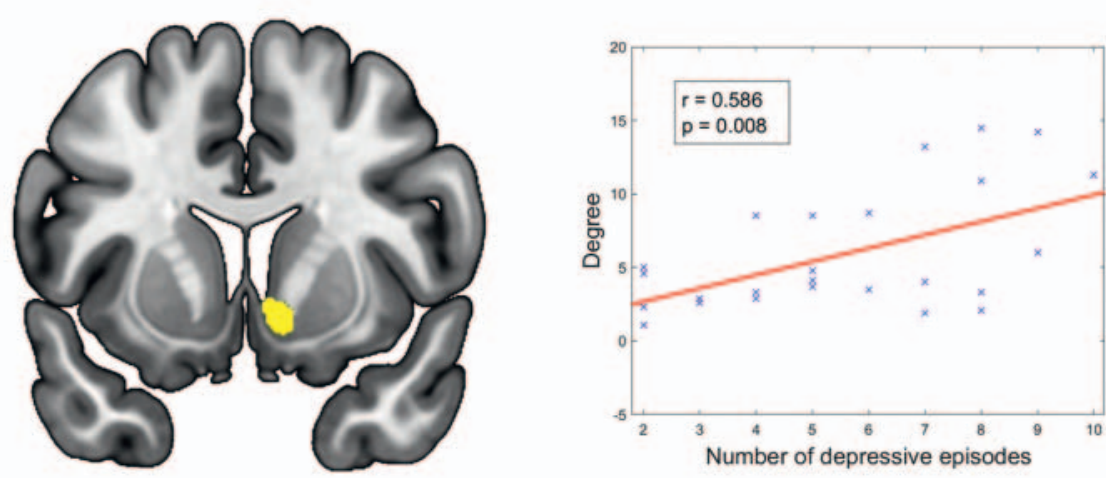

- Fig. 3 Association between striatal network topology and number of depressive episodes. Left column: regions of interest based on HarvardOxford brain atlas. Right column: association between nodal graph scores and number of depressive episodes (partial correlation analysis with medication, current symptom severity, total disease duration in years, and brain atrophy as covariates-of-no-interest).

- Abb. 3 Assoziation zwischen striataler Netzwerk-Topologie und der Anzahl depressiver Episoden. Linke Spalte: Regions of interest basierend auf dem Harvard-Oxford-Gehirnatlas. Rechte Spalte: Assoziation zwischen nodalen Graphen-Scores und der Anzahl depressiver Episoden (partielle Korrelations-Analyse mit Medikation, gegenwärtiger Schwere der Symptomatik, gesamte Krankheitsdauer in Jahren und Gehirnatrophie als Kontrollvariablen).

rently widespread use in neuroimaging. However, the exact mechanisms of neurovascular coupling, which links neuronal activity and BOLD signal, could not be resolved so far. Potential contributing factors comprise interneurons [53], astrocytes [54], and pericytes [55]. Moreover, interpretation of rs-fMRI data relies on the assumption that neurovascular coupling functions as normal. However, it has been shown that neurovascular coupling can be impaired in patients with hypertension or carotid stenosis [56]. Critically, these sources of non-neural noise, such as head motion, cardio-respiratory or vegetative factors, might differ between patients and controls: for example, head motion is frequently more pronounced in patients. It has been shown that head motion influences functional connectivity-based network measures [57]. Therefore, such group-differential non-neural noise could artifi- cially introduce between-group variance which might be mistakenly attributed to neural sources.

Second, rs-fMRI measures are still not reliably replicable due to high variability both across and within subjects, as well as across scanners, sequences, etc. One way to address this issue is to increase the signal-to-noise ratio of rs-fMRI measures by accounting for physiological (e. g., cardiac or respiratory) fluctuations; this would reduce non-neuronal contributions to the BOLD signal [58]. For example, one could increase the sampling rate [59] or control for physiological parameters measured during rs-fMRI [60]. However, further technical innovations are needed to reliably improve the signal-to-noise-ratio of rs-fMRI measurements in order to make them suitable for clinical applications. 
As a specific instance of the problem outlined above, there are difficulties in replicating connectome-based results on an individual level. Current knowledge, for example about connectome impairments in MDD, is based on group statistics. However, on an individual level, these group trends are not reliably observed. This issue probably represents the largest obstacle for translation of connectome approaches into the clinical routine.

Third, connectome-based measures are influenced - with varying magnitude - by methodological factors. For example, scan duration, preprocessing steps (such as frequency band filtering, regression of global signal, correlation method to construct graph edges, consideration of edges with negative values, graph binarization, etc.), but also the graph score itself influence the reliability of graph scores [61, 62]. Furthermore, graph node definition has a large effect on network properties. Most studies use atlases which define brain regions based on histology, macroscopic anatomy, or function. However, definitions of regions are often rough, as many details of human brain organization are still unknown. Therefore, a single atlas region might contain several functionally diverse subunits. Moreover, the type and spatial scale of brain parcellations significantly affect connectome measures [63, 64]. Another way of graph construction is to define nodes as voxels [65]. This, however, creates computational problems due to the large amount of data, although dimensionality reduction approaches are a promising tool to circumvent this issue [66].

\section{Conclusion}

Biomarkers based on functional connectome analyses of the brain are associated with the course of major depressive disorder. Therefore, they are promising candidates for the assessment of depressive relapse risk.

\section{Conflict of Interest}

The authors declare that they have no conflict of interest.

\section{References}

[1] Kessler RC, Birnbaum H, Bromet E et al. Age differences in major depression: results from the National Comorbidity Survey Replication (NCS-R). Psychol Med 2010; 40: 225-237

[2] American Psychiatric Association. Diagnostic and Statistical Manual of Mental Disorders, Fifth Edition. Arlington: VA: American Psychiatric Association; 2013

[3] Bradvik L, Mattisson C, Bogren M et al. Long-term suicide risk of depression in the Lundby cohort 1947-1997-severity and gender. Acta Psychiatr Scand 2008; 117: 185-191

[4] Hardeveld F, Spijker ], De Graaf R et al. Prevalence and predictors of recurrence of major depressive disorder in the adult population. Acta Psychiatr Scand 2010; 122: 184 - 191

[5] Keller MB, Boland RJ. Implications of failing to achieve successful longterm maintenance treatment of recurrent unipolar major depression. Biol Psychiatry 1998; 44: $348-360$

[6] Videbech P, Ravnkilde B. Hippocampal volume and depression: a metaanalysis of MRI studies. Am J Psychiatry 2004; 161: 1957-1966
[7] Wise T, Radua J, Via E et al. Common and distinct patterns of grey-matter volume alteration in major depression and bipolar disorder: evidence from voxel-based meta-analysis. Mol Psychiatry 2017; 22: 1455-1463

[8] MacQueen GM, Campbell S, McEwen BS et al. Course of illness, hippocampal function, and hippocampal volume in major depression. Proc Natl Acad Sci U S A 2003; 100: 1387-1392

[9] Kronmuller KT, Pantel ], Kohler S et al. Hippocampal volume and 2-year outcome in depression. Br J Psychiatry 2008; 192: 472-473

[10] Frodl T, Jager M, Smajstrlova I et al. Effect of hippocampal and amygdala volumes on clinical outcomes in major depression: a 3-year prospective magnetic resonance imaging study. J Psychiatry Neurosci 2008; 33 : $423-430$

[11] Sporns O, Tononi G, Kotter R. The human connectome: A structural description of the human brain. PLoS Comput Biol 2005; 1: e42

[12] Bullmore ET, Sporns O. Complex brain networks: graph theoretical analysis of structural and functional systems. Nat Rev Neurosci 2009; 10: $186-198$

[13] Biswal B, Yetkin FZ, Haughton VM et al. Functional connectivity in the motor cortex of resting human brain using echo-planar MRI. Magn Reson Med 1995; 34: 537 - 541

[14] Fox MD, Raichle ME. Spontaneous fluctuations in brain activity observed with functional magnetic resonance imaging. Nat Rev Neurosci 2007; 8: $700-711$

[15] Ogawa S, Lee TM, Kay AR et al. Brain magnetic resonance imaging with contrast dependent on blood oxygenation. Proc Natl Acad Sci U S A 1990; 87: $9868-9872$

[16] Hillman EM. Coupling mechanism and significance of the BOLD signal: a status report. Annu Rev Neurosci 2014; 37: 161 - 181

[17] Raichle ME. Behind the scenes of functional brain imaging: a historical and physiological perspective. Proc Natl Acad Sci U S A 1998; 95: 765 772

[18] Rubinov M, Sporns O. Complex network measures of brain connectivity: uses and interpretations. Neuroimage 2010; 52: 1059-1069

[19] Girvan M, Newman ME. Community structure in social and biological networks. Proc Natl Acad Sci U S A 2002; 99: 7821 - 7826

[20] Ravasz E, Somera AL, Mongru DA et al. Hierarchical organization of modularity in metabolic networks. Science 2002; 297: 1551 - 1555

[21] Guimera R, Mossa S, Turtschi A et al. The worldwide air transportation network: Anomalous centrality, community structure, and cities' global roles. Proc Natl Acad Sci U S A 2005; 102: 7794 - 7799

[22] van den Heuvel MP, Bullmore ET, Sporns O. Comparative Connectomics. Trends Cogn Sci 2016; 20: 345-361

[23] van den Heuvel MP, Scholtens LH, de Reus MA et al. Associated Microscale Spine Density and Macroscale Connectivity Disruptions in Schizophrenia. Biol Psychiatry 2016; 80: 293 - 301

[24] Fornito A, Zalesky A, Pantelis C et al. Schizophrenia, neuroimaging and connectomics. Neuroimage 2012; 62: 2296-2314

[25] Stam C]. Modern network science of neurological disorders. Nat Rev Neurosci 2014; 15: 683-695

[26] Fornito A, Zalesky A, Breakspear M. The connectomics of brain disorders. Nat Rev Neurosci 2015; 16: 159-172

[27] Gong Q, He Y. Depression, Neuroimaging and Connectomics: A Selective Overview. Biol Psychiatry 2015; 77: $223-235$

[28] Lo CY, Wang PN, Chou KH et al. Diffusion tensor tractography reveals abnormal topological organization in structural cortical networks in Alzheimer's disease. J Neurosci 2010; 30: 16876-16885

[29] Skidmore F, Korenkevych D, Liu Y et al. Connectivity brain networks based on wavelet correlation analysis in Parkinson fMRI data. Neurosci Lett 2011; 499: $47-51$ 
[30] Shu N, Liu Y, Li K et al. Diffusion tensor tractography reveals disrupted topological efficiency in white matter structural networks in multiple sclerosis. Cereb Cortex 2011; 21: 2565-2577

[31] Pandit AS, Expert P, Lambiotte R et al. Traumatic brain injury impairs small-world topology. Neurology 2013; 80: 1826-1833

[32] Zhang Z, Liao W, Chen $\mathrm{H}$ et al. Altered functional-structural coupling of large-scale brain networks in idiopathic generalized epilepsy. Brain 2011; 134: 2912-2928

[33] Lynall ME, Bassett DS, Kerwin R et al. Functional connectivity and brain networks in schizophrenia. J Neurosci 2010; 30: 9477 -9487

[34] van den Heuvel MP, Sporns O, Collin G et al. Abnormal rich club organization and functional brain dynamics in schizophrenia. JAMA Psychiatry 2013; 70: 783-792

[35] Shin D], Jung WH, He Y et al. The effects of pharmacological treatment on functional brain connectome in obsessive-compulsive disorder. Biol Psychiatry 2014; 75: 606-614

[36] Reess T], Rus OG, Schmidt R et al. Connectomics-based structural network alterations in obsessive-compulsive disorder. Transl Psychiatry 2016; 6: e882

[37] Bai F, Shu N, Yuan Y et al. Topologically convergent and divergent structural connectivity patterns between patients with remitted geriatric depression and amnestic mild cognitive impairment. J Neurosci 2012; 32: $4307-4318$

[38] Korgaonkar MS, Fornito A, Williams LM et al. Abnormal structural networks characterize major depressive disorder: a connectome analysis. Biol Psychiatry 2014; 76: 567-574

[39] Qin J, Wei M, Liu H et al. Abnormal brain anatomical topological organization of the cognitive-emotional and the frontoparietal circuitry in major depressive disorder. Magn Reson Med 2014; 72: 1397-1407

[40] Zeng J, Luo Q, Du L et al. Reorganization of Anatomical Connectome following Electroconvulsive Therapy in Major Depressive Disorder. Neural Plast 2015; 2015: 271674

[41] Zhang J, Wang J, Wu Q et al. Disrupted brain connectivity networks in drug-naive, first-episode major depressive disorder. Biol Psychiatry 2011; 70: 334-342

[42] Meng C, Brandl F, Tahmasian M et al. Aberrant topology of striatum's connectivity is associated with the number of episodes in depression. Brain 2014; 137: 598-609

[43] Lord A, Horn D, Breakspear M et al. Changes in community structure of resting state functional connectivity in unipolar depression. PLoS One 2012; 7: e41282

[44] Bohr IJ, Kenny E, Blamire A et al. Resting-state functional connectivity in late-life depression: higher global connectivity and more long distance connections. Front Psychiatry 2012; 3: 116

[45] Jin C, Gao C, Chen C et al. A preliminary study of the dysregulation of the resting networks in first-episode medication-naive adolescent depression. Neurosci Lett 2011; 503: 105-109

[46] Tao H, Guo S, Ge T et al. Depression uncouples brain hate circuit. Mol Psychiatry 2013; 18: $101-111$

[47] Feinberg DA, Setsompop K. Ultra-fast MRI of the human brain with simultaneous multi-slice imaging. J Magn Reson 2013; 229: 90 - 100
[48] Preibisch C, Castrillon G], Buhrer M et al. Evaluation of Multiband EPI Acquisitions for Resting State fMRI. PLoS One 2015; 10: e0136961

[49] Attwell D, Buchan AM, Charpak S et al. Glial and neuronal control of brain blood flow. Nature 2010; 468: 232-243

[50] Logothetis NK, Pauls ], Augath M et al. Neurophysiological investigation of the basis of the fMRI signal. Nature 2001; 412: 150-157

[51] Pan W], Thompson G], Magnuson ME et al. Infraslow LFP correlates to resting-state fMRI BOLD signals. Neuroimage 2013; 74: 288-297

[52] Matsui T, Murakami T, Ohki K. Transient neuronal coactivations embedded in globally propagating waves underlie resting-state functional connectivity. Proc Natl Acad Sci U S A 2016; 113: 6556-6561

[53] Cauli B, Tong XK, Rancillac A et al. Cortical GABA interneurons in neurovascular coupling: relays for subcortical vasoactive pathways. J Neurosci 2004; 24: $8940-8949$

[54] Takano T, Tian GF, Peng W et al. Astrocyte-mediated control of cerebral blood flow. Nat Neurosci 2006; 9: 260-267

[55] Peppiatt CM, Howarth C, Mobbs P et al. Bidirectional control of CNS capillary diameter by pericytes. Nature 2006; 443: 700-704

[56] Girouard H, ladecola C. Neurovascular coupling in the normal brain and in hypertension, stroke, and Alzheimer disease. J Appl Physiol (1985) 2006; 100: $328-335$

[57] Van Dijk KR, Sabuncu MR, Buckner RL. The influence of head motion on intrinsic functional connectivity MRI. Neuroimage 2012; 59: 431-438

[58] Fox MD, Greicius M. Clinical applications of resting state functional connectivity. Front Syst Neurosci 2010; 4: 19

[59] Cordes D, Haughton VM, Arfanakis K et al. Frequencies contributing to functional connectivity in the cerebral cortex in "resting-state" data. AJNR Am J Neuroradiol 2001; 22: 1326-1333

[60] Glover GH, Li TQ, Ress D. Image-based method for retrospective correction of physiological motion effects in fMRI: RETROICOR. Magn Reson Med 2000; 44: 162 - 167

[61] Braun U, Plichta MM, Esslinger C et al. Test-retest reliability of restingstate connectivity network characteristics using fMRI and graph theoretical measures. Neuroimage 2012; 59: 1404-1412

[62] Andellini M, Cannata V, Gazzellini S et al. Test-retest reliability of graph metrics of resting state MRI functional brain networks: A review. J Neurosci Methods 2015; 253: 183-192

[63] Wang J, Wang L, Zang Y et al. Parcellation-dependent small-world brain functional networks: a resting-state fMRI study. Hum Brain Mapp 2009; 30: $1511-1523$

[64] Zalesky A, Fornito A, Harding IH et al. Whole-brain anatomical networks: does the choice of nodes matter? Neuroimage 2010; 50: 970-983

[65] van den Heuvel MP, Stam C], Boersma M et al. Small-world and scalefree organization of voxel-based resting-state functional connectivity in the human brain. Neuroimage 2008; 43: 528-539

[66] Tagliazucchi E, Siniatchkin M, Laufs $\mathrm{H}$ et al. The Voxel-Wise Functional Connectome Can Be Efficiently Derived from Co-activations in a Sparse Spatio-Temporal Point-Process. Front Neurosci 2016; 10: 381 